\title{
Technical note: Assessment of the oxygen pulse and heart rate method using respiration chambers and comparative slaughter for measuring heat production of cattle
}

\author{
D. B. Oss, ${ }^{*} \dagger$ M. I. Marcondes, ${ }^{* 1}$ F. S. Machado, $\ddagger$ T. R. Tomich, $\ddagger$ M. L. Chizzotti, ${ }^{\star}$ M. M. Campos, $\ddagger$ \\ and L. G. R. Pereirał \\ *Universidade Federal de Viçosa, Viçosa, MG, Brazil, 36570-900 \\ †CAPES, Ministério da Educação, Brasília, DF, Brazil, 70040-020 \\ ‡Empresa Brasileira de Pesquisa Agropecuária, Embrapa Gado de Leite, Juiz de Fora, MG, Brazil, 36038-330
}

\begin{abstract}
The objective of this study was to assess the oxygen pulse and heart rate $\left(\mathrm{O}_{2} \mathrm{P}-\mathrm{HR}\right)$ technique using the respiration chamber (RC) and comparative slaughter (CS) methods for measuring the heat production (HP) of crossbred (Holstein $\times$ Gyr) yearling bulls. Twenty-four bulls were used. Six bulls were slaughtered at the beginning of the experiment as a reference group to estimate the initial empty body weight (BW) and energy content of the remaining animals. The remaining bulls were assigned to a completely randomized design with 3 levels of dry matter intake, with 6 replicates. The levels of dry matter intake were $1.2 \%$ of $\mathrm{BW}, 1.8 \%$ of $\mathrm{BW}$ and ad libitum, with target orts of $5 \%$. The bulls were fed a diet consisting of $59.6 \%$ corn silage and $40.4 \%$ concentrate on a dry matter basis. The HP $\left(\mathrm{kcal} / \mathrm{BW}^{0.75}\right)$ was measured using 3 techniques, first using $\mathrm{O}_{2} \mathrm{P}-\mathrm{HR}$, followed by the RC and CS methods. The HP did not differ among assessed techniques, averaging $162.7 \mathrm{kcal} /$ $\mathrm{BW}^{0.75}$. The intercepts of the linear regressions (mean $\pm \mathrm{SE})$ were $64.82 \pm 25.515\left(\mathrm{H}_{0}\right.$ : intercept $=0 ; P=$ $0.024), 33.77 \pm 13.418\left(\mathrm{H}_{0}\right.$ : intercept $\left.=0\right)$, and 50.02 $\pm 27.495\left(\mathrm{H}_{0}\right.$ : intercept $\left.=0\right)$ for $\mathrm{O}_{2} \mathrm{P}-\mathrm{HR}$ versus $\mathrm{RC}$, CS versus $\mathrm{RC}$, and $\mathrm{O}_{2} \mathrm{P}-\mathrm{HR}$ versus $\mathrm{CS}$, respectively. The slopes of the linear regressions were $0.59 \pm 0.153$ $\left(\mathrm{H}_{0}\right.$ : slope $\left.=1\right), 0.88 \pm 0.081\left(\mathrm{H}_{0}\right.$ : slope $\left.=1\right)$, and 0.62 $\pm 0.155\left(\mathrm{H}_{0}\right.$ : slope $\left.=1\right)$ for $\mathrm{O}_{2} \mathrm{P}-\mathrm{HR}$ versus $\mathrm{RC}, \mathrm{CS}$ versus $\mathrm{RC}$, and $\mathrm{O}_{2} \mathrm{P}-\mathrm{HR}$ versus $\mathrm{CS}$, respectively. The coefficients of determination were $0.52,0.90$, and 0.52 for $\mathrm{O}_{2} \mathrm{P}-\mathrm{HR}$ versus $\mathrm{RC}$, CS versus $\mathrm{RC}$, and $\mathrm{O}_{2} \mathrm{P}-\mathrm{HR}$ versus CS, respectively. The concordance correlation coefficients, 0.70 and 0.68 , were moderate for $\mathrm{O}_{2} \mathrm{P}-\mathrm{HR}$ versus $\mathrm{RC}$ and $\mathrm{O}_{2} \mathrm{P}-\mathrm{HR}$ versus $\mathrm{CS}$, respectively, but high, 0.90, for CS versus RC. The between-animal coef-
\end{abstract}

Received March 10, 2016.

Accepted July 12, 2016.

${ }^{1}$ Corresponding author: marcosinaciomarcondes@gmail.com ficient of variation was greater for the $\mathrm{O}_{2} \mathrm{P}-\mathrm{HR}$ method (16.6\%) compared with RC $(7.7 \%)$ or CS $(6.7 \%)$. We conclude that there was an agreement among the HP measurements detected using the assessed methods and that $\mathrm{O}_{2} \mathrm{P}-\mathrm{HR}$ is able to predict $\mathrm{HP}$ in cattle with great accuracy but only moderate precision. Therefore, the $\mathrm{O}_{2} \mathrm{P}-\mathrm{HR}$ method may have limitations in terms of assessing HP in low numbers of replications due to greater between-animal coefficient of variation than either the RC or CS methods.

Key words: heart rate, heat production, oxygen pulse

\section{Technical Note}

Heat production $(\mathbf{H P})$ of cattle can be determined under controlled and confined conditions by using the respiration chamber (RC) method; however, these conditions do not reflect free-ranging animals or commercial cattle in feedlots or pastures. Also, capital investment for $\mathrm{RC}$ is high, training of animals is required, and the behavior of animal may be altered from that which occurs under most production settings (e.g., low activity and reductions in DMI). In an attempt to overcome the limitations of measuring HP in the environment of cattle, HP can also be measured using the comparative slaughter method (CS), as this technique allows the evaluation of animals that are being raised in several production conditions. However, CS is terminal, laborious, and requires accurate estimates of DMI and metabolizable energy intake (MEI) and thus can introduce significant errors; besides, it is able to provide only one $\mathrm{HP}$ value on average for all of the experiment.

The $\mathrm{O}_{2} \mathrm{P}-\mathrm{HR}$ method is an alternative technique for measuring HP that is based on long-term measurements (24-h periods) of the heart rate (HR) of free-range animals and on short-term measurements of oxygen pulse $\left(\mathrm{O}_{2} \mathbf{P} ; \mathrm{mL}\right.$ of $\mathrm{O}_{2}$ consumed/heart beat), which are measured by attaching a face mask (FM) to the animal's nose (Brosh, 2007). 
Few experiments have been conducted to examine the reliability of the $\mathrm{O}_{2} \mathrm{P}-\mathrm{HR}$ method in measuring the HP of cows (Arieli et al., 2002; Brosh et al., 2002). However, to our knowledge, no studies have compared $\mathrm{O}_{2} \mathrm{P}-\mathrm{HR}$ with the more traditional techniques ( $\mathrm{RC}$ and CS) of determining HP in cattle energetics research (Arieli et al., 2002; compared $\mathrm{O}_{2} \mathrm{P}-\mathrm{HR}$ with CS in sheep rather than cattle). The use of $\mathrm{O}_{2} \mathrm{P}-\mathrm{HR}$ method as an alternative method can be useful in studies including genetic and efficiency selection, evaluation of physiological stage or growth stage and also different feeding paradigms.

Therefore, the objective of this study was to compare the $\mathrm{O}_{2} \mathrm{P}-\mathrm{HR}, \mathrm{RC}$, and CS methods of measuring and assessing variation in HP in cattle. We hypothesized that the $\mathrm{O}_{2} \mathrm{P}-\mathrm{HR}$ method would predict $\mathrm{HP}$ comparable to the RC and CS techniques for these same growing bulls.

The present study followed the guidelines of the Ethics Committee in Animal Use of the Universidade Federal de Viçosa (process number 44/2012). The experiment was conducted at the Multi-Use Complex on Livestock Bioefficiency and Sustainability at Embrapa Gado de Leite, in Coronel Pacheco, MG, Brazil, from August 2013 to February 2014.

Twenty-four Holstein $\times$ Gyr crossbred 10-mo-old bulls (initial BW $=155 \pm 24.6 \mathrm{~kg}$ ) were used. All bulls were adapted to the experimental diet before the initial slaughter over $30 \mathrm{~d}$ being fed the same level of DM: $2.0 \%$ of BW. After the adaptation period, bulls (184 $\pm 23.4 \mathrm{~kg}$ ) were randomly subdivided into 4 groups of 6 animals. One of those groups was designated as a baseline reference group and was slaughtered at the beginning of the experiment to measure the initial body energy content in their empty BW (EBW) to facilitate the CS method. The 3 remaining groups were fed at 3 different DMI: (1) restricted to $1.2 \%$ of $\mathrm{BW},(2)$ restricted to $1.8 \%$ of BW, or (3) ad libitum with target $5 \%$ orts. These treatments were selected to introduce the necessary variation in MEI to assess the validity of the method. One bull from the ad libitum group had to be removed from the experiment due to health issues. Throughout the experiment, bulls were housed in a tie stall barn with free access to water and fed a diet consisting of corn silage and concentrate (59.6: $40.4 \mathrm{DM}$ basis $)$ once daily $(0830 \mathrm{~h})$. The concentrate was composed of soybean meal $(24.8 \%)$, ground corn $(67.9 \%)$, urea $(2.4 \%)$, mineral mix $(3.5 \%)$, and limestone $(1.4 \%)$. The DM feed offered and refused was weighed to determine total daily DMI. The estimated $\mathrm{ME}$ content of the diet was $2.4 \mathrm{Mcal} / \mathrm{kg}$ of $\mathrm{DM}$ on average. The ME content of the diet was determined by multiplying digestible energy by 0.82 (NRC, 1996) taking into account the DM digestibility coefficients of each animal. Although the fixed ratio ME:digestible energy (DE) of 0.82 (NRC, 1996) has been accepted in many publications, this ratio might change as MEI increases [i.e., Chaokaur et al., 2015, who determined energy balance of Brahman bulls raised on increasing dietary allocations observed ME:DE ratio of $0.82,0.86$, 0.87 , and 0.88 for maintenance $(\mathbf{M}), 1.4 \times \mathrm{M}, 1.8 \times$ $\mathrm{M}$, and ad libitum groups, respectively]. The digestibility coefficients in our study were obtained from 2 digestibility trials conducted at 2 points throughout the experiment: 2 mo after the reference slaughter and 2 mo before the final slaughter. The DM digestibility coefficients did not differ between trials. The digestibility trial consisted of $3 \mathrm{~d}$ of total feces and urine collection as described by Costa e Silva et al. (2015).

Treated bulls were slaughtered at the end of the experiment to measure the final body energy content in their final EBW for CS calculations. The experiment lasted 173, 171, and $168 \mathrm{~d}$ for the $1.2 \%$ of $\mathrm{BW}, 1.8 \%$ of BW and ad libitum groups, respectively, after which the animals were slaughtered. The slaughters followed the same procedures described by Costa e Silva et al. (2015).

The bulls were accustomed to the FM for a period of $2 \mathrm{wk}$ before measurements. Bulls were placed in a squeeze chute and the FM was fitted for two 20-min periods (morning and afternoon). Following the training period, $3 \mathrm{O}_{2} \mathrm{P}(\mathrm{mL} /$ heart beat) measurements were collected over a 3 -d period with measurements made about $6 \mathrm{~h}$ after feeding, separated by $3 \mathrm{~d}$ of HR (beats/ min) measurements at the tie stall.

The $\mathrm{O}_{2}$ consumption data were recorded using a Sable System (Sable Systems International, Las Vegas, NV) attached to the FM. Details about the gas measurements were described by Oss et al. (2016). Samples from the FM were collected at 20-s intervals and recorded at 1-min intervals over 20 min, with ambient air collected 5 min before and after the 20-min measurements to establish baseline gas levels. All data were recorded using an automated data acquisition program (Expedata, Sable Systems International). The $\mathrm{O}_{2}$ consumption $\left(\mathrm{VO}_{2} ; \mathrm{mL} / \mathrm{min}\right)$ was calculated from the product of mass flow measurements of the atmospheric air corrected for standard temperature $(273.5 \mathrm{~K})$ and pressure (101.325 kPa) conditions (STP) and difference in average from FM $\left[\mathrm{O}_{2} \mathrm{fm}, \%\right.$ and baseline $\left(\mathrm{O}_{2} \mathrm{~b} ; \%\right)$, $\mathrm{O}_{2}$ concentration measurements over $30 \mathrm{~min}$ ] as follows:

$$
\mathrm{VO}_{2}=\left[\mathrm{STP} \times\left(\mathrm{O}_{2} \mathrm{fm}-\mathrm{O}_{2} \mathrm{~b}\right)\right]
$$

The HR was recorded using a Polar equine transmitter and monitor (model RS800CX, Polar Electro Inc., 
Kempele, Finland). The transmitters were embedded in a 10-cm-wide girth strap with a Velcro latch placed around the bulls' girth behind the shoulders. The negative electrode was positioned on the right side and the positive electrode on the opposite side of the bulls, parallel to the left elbow. The area around the electrodes was shaved and a conductivity gel was applied to increase conductance.

The HR measurements during the $\mathrm{O}_{2}$ consumption measurement and the $3 \mathrm{~d}$ of $\mathrm{HR}$ at the tie stall were averaged and recorded every $60 \mathrm{~s}$. To obtain a representative daily average HR for each measurement day, a deviation was calculated for each $60 \mathrm{~s}$ of HR recorded, taking into account the average of $5 \mathrm{~min}$ before and 5 min after each minute recorded. Outliers were identified when this deviation was over $30 \%$. The HR days were then overlapped and an average was calculated.

The $\mathrm{O}_{2} \mathrm{P}(\mathrm{mL} /$ heart beat) was determined by the average $\mathrm{O}_{2}$ consumption per min over the average HR per min during the same 20-min period. Total daily $\mathrm{O}_{2}$ consumption $(\mathrm{L} / \mathrm{d})$ was calculated from the average of $\mathrm{O}_{2} \mathrm{P}$ and average daily HR. Daily HP was then calculated as the product of total daily $\mathrm{O}_{2}$ consumption and the constant $20.47 \mathrm{KJ}$ per liter of $\mathrm{O}_{2}$ (McLean, 1972).

Two weeks after performing the $\mathrm{O}_{2} \mathrm{P}-\mathrm{HR}$ method, the $\mathrm{HP}$ of the bulls was again estimated but using indirect open-circuit RC. Two RC were used. The chamber's design and operation were described by Machado et al. (2016). Bulls were housed in the chambers for two 24-h periods for HP measurement. Bulls were placed in the chamber, feed was delivered, the chamber was closed, and measurements were initiated. After $24 \mathrm{~h}$ the measurements were interrupted and the bulls were removed to clean the chambers. The daily $\mathrm{O}_{2}$ consumption and $\mathrm{CO}_{2}$ and $\mathrm{CH}_{4}$ production were measured over $24 \mathrm{~h}$ with correction for the $\mathrm{CO}_{2}$ and $\mathrm{CH}_{4}$ recovery levels in each chamber, which were 99.0 and $98.0 \%$, respectively. The HP was calculated based on Brouwer (1965). To compute the energy loss in urine as $\mathrm{N}$, the urinary $\mathrm{N}$ was determined from samples obtained from the digestibility trials.

For the comparison of HP among the 3 techniques assessed, we assumed that HP remained the same in terms of kilocalories per $\mathrm{BW}^{0.75}$ along the experimental period once bulls were under very low performance due to the intake levels under which they were. This assumption made us able determine $\mathrm{HP}$ by $\mathrm{RC}$ and $\mathrm{O}_{2} \mathrm{P}-\mathrm{HR}$ methods only once during the experimental period. Therefore, we suggest that in future studies, HP by $\mathrm{RC}$ or $\mathrm{O}_{2} \mathrm{P}-\mathrm{HR}$ methods in growing animals with greater performance be determined at least 2 times during the growing period, one during each half of the experimental period.
With regard to CS, the HP was calculated as the difference between the MEI and retained energy. The retained energy was calculated as the difference between the final energy content and the initial energy content in the EBW of bulls.

All HP were expressed as kilocalories per $\mathrm{BW}^{0.75}$. Data were analyzed using the GLM procedure of SAS (SAS Institute Inc., Cary, NC). Significance among HP means was declared at $P \leq 0.05$. The agreement between HP using $\mathrm{O}_{2} \mathrm{P}-\mathrm{HR}$ versus $\mathrm{RC}$, CS versus $\mathrm{RC}$, and $\mathrm{O}_{2} \mathrm{P}-\mathrm{HR}$ versus $\mathrm{CS}$ methods was analyzed using the Model Evaluation System (Tedeschi, 2006; http:// nutritionmodels.tamu.edu/models/mes/) in which predicted values ( $\mathrm{RC}$ or $\mathrm{CS})$ and observed $\left(\mathrm{O}_{2} \mathrm{P}-\mathrm{HR}\right.$ or $\mathrm{CS})$ values were analyzed for accuracy and precision using several variables. These variables included linear regression of observed and predicted values, $t$-tests to identify the significance of parameters (intercept $=0$ and slope $=1$; Neter et al., 1996), coefficients of determination, concordance correlation coefficients (CCC; Lin, 1989), accuracy ( $\mathbf{C b}$; Liao, 2003), the mean square error of prediction, and its decomposition into mean bias, systematic bias, and random errors (Bibby and Toutenburg, 1977). The estimated means and standard deviations were used to compute between-animal coefficients of variation in $\mathrm{HP}\left(\mathrm{kcal} / \mathrm{BW}^{0.75}\right)$.

The relationships between $\mathrm{HP}\left(\mathrm{kcal} / \mathrm{BW}^{0.75}\right)$ measured using $\mathrm{O}_{2} \mathrm{P}-\mathrm{HR}$ versus $\mathrm{RC}$ and CS versus RC methods are illustrated in Figure 1, whereas the comparison between $\mathrm{O}_{2} \mathrm{P}-\mathrm{HR}$ versus CS is illustrated in Figure 2. Table 1 contains the description of the database of HP

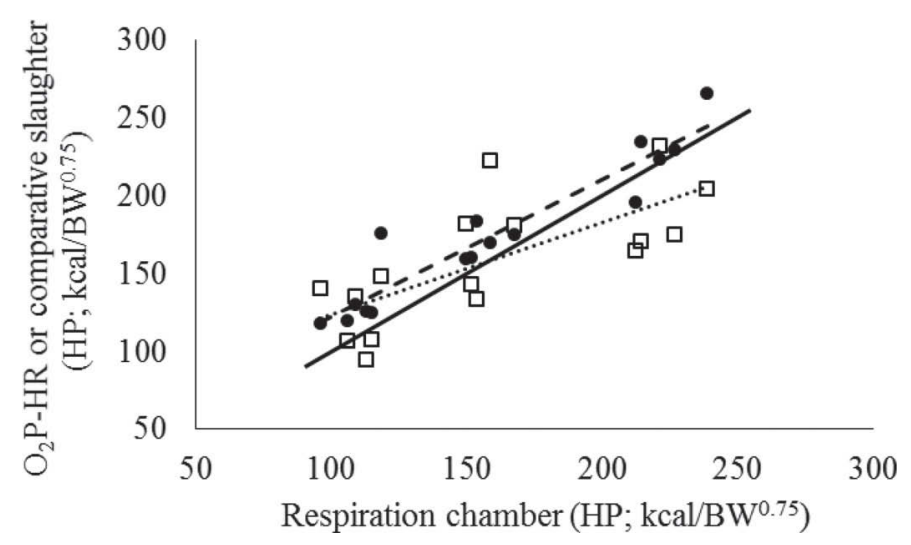

Figure 1. Relationships between heat production (HP; kcal/ $\left.\mathrm{BW}^{0.75}\right)$ measured using oxygen pulse and heart rate $\left(\mathrm{O}_{2} \mathrm{P}-\mathrm{HR}\right)$ versus respiration chamber $(\mathrm{RC})$ and comparative slaughter $(\mathrm{CS})$ versus $\mathrm{RC}$ methods of individual crossbred (Holstein $\times$ Gyr) yearling bulls fed at different intake levels. Open symbols and dotted line are related to $\mathrm{O}_{2} \mathrm{P}-\mathrm{HR}$ versus RC. Solid symbols and dashed line are related to CS versus RC. The solid line is the line $y=x$. 
Table 1. Description of the database of heat production (HP; kcal/BW ${ }^{0.75}$ ) measurements used to assess the oxygen pulse and heart rate $\left(\mathrm{O}_{2} \mathrm{P}-\mathrm{HR}\right)$ in comparison with respiration chamber $(\mathrm{RC})$ and comparative slaughter (CS) methods

\begin{tabular}{lcccccc}
\hline Method & Mean & Minimum & Maximum & SD & $P$-value & CV $(\%)$ \\
\hline $\mathrm{O}_{2} \mathrm{P}-\mathrm{HR}$ & 157.1 & 94.6 & 232.5 & 40.03 & & 16.6 \\
$\mathrm{RC}$ & 159.4 & 95.8 & 238.9 & 49.00 & 0.076 & 7.6 \\
$\mathrm{CS}$ & 171.6 & 118.2 & 266.1 & 46.23 & & 6.7 \\
\hline
\end{tabular}

measurements for each method used. Related descriptive statistics are presented in Table 2.

For comparisons of $\mathrm{O}_{2} \mathrm{P}-\mathrm{HR}$ versus $\mathrm{RC}$ and $\mathrm{O}_{2} \mathrm{P}-\mathrm{HR}$ versus CS, the regression analysis indicated that the slopes were different from unity $(P<0.050)$; however, for comparison CS versus RC slope did not differ from $1(P=0.173)$. The slopes of the linear regressions $($ mean $\pm \mathrm{SE})$ were $0.59 \pm 0.153\left(\mathrm{H}_{0}\right.$ : slope $=1 ; P=$ $0.018), 0.88 \pm 0.081\left(\mathrm{H}_{0}\right.$ : slope $\left.=1 ; P=0.173\right)$, and $0.62 \pm 0.155\left(\mathrm{H}_{0}\right.$ : slope $\left.=1 ; P=0.028\right)$ for $\mathrm{O}_{2} \mathrm{P}-\mathrm{HR}$ versus $\mathrm{RC}$, CS versus $\mathrm{RC}$, and $\mathrm{O}_{2} \mathrm{P}-\mathrm{HR}$ versus $\mathrm{CS}$, respectively (Table 2).

The intercept of the linear regression was different from zero $(P<0.050)$ for $\mathrm{O}_{2} \mathrm{P}-\mathrm{HR}$ versus $\mathrm{RC}$ and $\mathrm{CS}$ versus $\mathrm{RC}$ but did not differ from zero for $\mathrm{O}_{2} \mathrm{P}-\mathrm{HR}$ versus CS $(P=0.089)$. The intercepts of the linear regressions $($ mean $\pm \mathrm{SE})$ were $64.82 \pm 25.515\left(\mathrm{H}_{0}\right.$ : intercept $=0 ; P=0.024), 33.77 \pm 13.418\left(\mathrm{H}_{0}\right.$ : intercept $=0 ; P=0.025)$, and $50.02 \pm 27.495\left(\mathrm{H}_{0}\right.$ : intercept $=$ $0 ; P=0.089$ ) for $\mathrm{O}_{2} \mathrm{P}-\mathrm{HR}$ versus $\mathrm{RC}$, CS versus $\mathrm{RC}$, and $\mathrm{O}_{2} \mathrm{P}-\mathrm{HR}$ versus $\mathrm{CS}$, respectively (Table 2). In a study in which a comparison between $\mathrm{O}_{2} \mathrm{P}-\mathrm{HR}$ versus CS was performed using sheep, a slope of 0.86 (closer to unity than our finding) and an intercept of 135.29 were found (Arieli et al., 2002). Slopes and intercepts different from unity and zero, respectively, are in this case indicative of low accuracy of the $\mathrm{O}_{2} \mathrm{P}-\mathrm{HR}$ method compared with $\mathrm{RC}$. However, the $\mathrm{Cb}$ values, another accuracy index, indicate great accuracy of the $\mathrm{O}_{2} \mathrm{P}-\mathrm{HR}$ method compared with RC (0.97) and CS (0.94); similarly, a great accuracy was observed for CS compared with RC (0.95).

The regression estimates of coefficient of determination for $\mathrm{O}_{2} \mathrm{P}-\mathrm{HR}$ versus $\mathrm{RC}$ was 0.52 , a moderate value compared with the coefficient of determination for CS versus $\mathrm{RC}$ (Table 2). The third comparison, $\mathrm{O}_{2} \mathrm{P}-\mathrm{HR}$ versus CS, also presented a moderate coefficient of determination, 0.52. The coefficient of determination is a good indicator of precision; the greater the coefficient of determination, the greater the precision (Tedeschi, 2006). Precision measures how close individual $\mathrm{O}_{2} \mathrm{P}-\mathrm{HR}$ and CS values are within each condition (treatment), whereas accuracy measures how close $\mathrm{O}_{2} \mathrm{P}-\mathrm{HR}$ and $\mathrm{CS}$ values are to the $\mathrm{RC}$ values, and also how close $\mathrm{O}_{2} \mathrm{P}-$ $\mathrm{HR}$ values are to $\mathrm{CS}$ values. Given these definitions of accuracy and precision, the $\mathrm{O}_{2} \mathrm{P}-\mathrm{HR}$ and CS methods

Table 2. Descriptive statistics of relationship between heat production (kcal/BW $\mathrm{BW}^{0.75}$ ) using oxygen pulse and heart rate $\left(\mathrm{O}_{2} \mathrm{P}-\mathrm{HR}\right)$ versus respiration chamber $(\mathrm{RC})$ and $\mathrm{O}_{2} \mathrm{P}-\mathrm{HR}$ versus comparative slaughter (CS) methods of individual crossbred (Holstein $\times$ Gyr) yearling bulls fed at different intake levels ${ }^{1}$

\begin{tabular}{|c|c|c|c|}
\hline \multirow[b]{2}{*}{ Item } & \multicolumn{3}{|c|}{ Method comparison } \\
\hline & $\mathrm{O}_{2} \mathrm{P}-\mathrm{HR}$ vs. $\mathrm{RC}$ & CS vs. RC & $\mathrm{O}_{2} \mathrm{P}-\mathrm{HR}$ vs. CS \\
\hline \multicolumn{4}{|l|}{ Regression } \\
\hline \multicolumn{4}{|l|}{ Intercept } \\
\hline Estimate & 64.82 & 33.77 & 50.02 \\
\hline $\mathrm{SE}$ & 25.515 & 13.418 & 27.495 \\
\hline$P$-value & 0.024 & 0.025 & 0.089 \\
\hline \multicolumn{4}{|l|}{ Slope } \\
\hline Estimate & 0.59 & 0.88 & 0.62 \\
\hline $\mathrm{SE}$ & 0.153 & 0.081 & 0.155 \\
\hline$P$-value & 0.018 & 0.173 & 0.028 \\
\hline $\mathrm{R}^{2}$ & 0.52 & 0.90 & 0.52 \\
\hline $\mathrm{CCC}$ & 0.70 & 0.90 & 0.68 \\
\hline $\mathrm{Cb}$ & 0.97 & 0.95 & 0.94 \\
\hline MSEP & $1,116.92$ & 469.17 & $1,219.63$ \\
\hline MB & $0.09(0.01 \%)$ & $233.92(49.86 \%)$ & $209.99(17.22 \%)$ \\
\hline $\mathrm{SB}$ & $375.47(33.62 \%)$ & $30.21(6.44 \%)$ & $284.35(23.31 \%)$ \\
\hline $\mathrm{RE}$ & $741.36(66.38 \%)$ & $205.03(43.70 \%)$ & $725.29(59.47 \%)$ \\
\hline
\end{tabular}

${ }^{1} \mathrm{CCC}=$ correlation and concordance coefficient. $\mathrm{H}_{0}$ : intercept $=0 . \mathrm{H}_{0}$ : slope $=1 . \mathrm{Cb}=$ bias correction factor. $\mathrm{MSEP}=$ mean square error of prediction. $\mathrm{MB}=$ mean bias. $\mathrm{SB}=$ systematic bias. $\mathrm{RE}=$ random errors. 


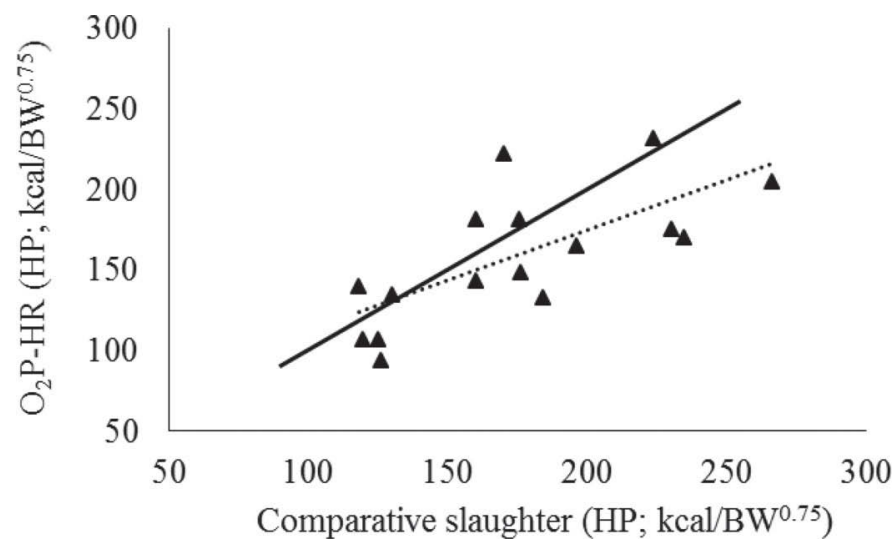

Figure 2. Relationship between heat production (HP; kcal/BW ${ }^{0.75}$ ) measured using oxygen pulse and heart rate $\left(\mathrm{O}_{2} \mathrm{P}-\mathrm{HR}\right)$ versus comparative slaughter (CS) methods of individual crossbred (Holstein $\times$ Gyr) yearling bulls fed at different intake levels. The solid line is the line $y=x$.

have the ability to estimate the "correct" values because they presented great accuracy $(\mathrm{Cb})$ compared with RC; however, the $\mathrm{O}_{2} \mathrm{P}-\mathrm{HR}$ is not as sensible as $\mathrm{CS}$ to measure values consistently because $\mathrm{O}_{2} \mathrm{P}-\mathrm{HR}$ method presented moderate precision whereas CS presented great precision $\left(\mathrm{R}^{2}\right)$. The moderate precision presented by the $\mathrm{O}_{2} \mathrm{P}-\mathrm{HR}$ method was also confirmed by the greater between-animal coefficient of variation (16.6\%) compared with RC (7.7\%) and CS (6.7\%).

It is difficult to point out which is better, accuracy or precision. According to Tedeschi (2006), it is easy to understand why accuracy could be argued as the most important measure as the true mean can be detected using an imprecise method simply by averaging a large number of data points. However, measurements using an accurate but imprecise method are unrealistic as they may interfere in the variation of means and consequently make it difficult to find differences between treatments using this technique.

Based on the discussion above, the $\mathrm{O}_{2} \mathrm{P}-\mathrm{HR}$ method has great accuracy and will provide good estimates of HP; however, to identify treatment differences in an experiment the sample size $(n)$ must be increased. The implication of a greater between-animal coefficient of variation is that to detect a treatment difference with a certain power, more animals (replicates) per treatment would be required with the $\mathrm{O}_{2} \mathrm{P}-\mathrm{HR}$ method compared with the RC or CS techniques; however, benefits of the technique are significant and it can complement a program to assess energy use as affected by many factors. Although more animals are required and multiple sampling is needed, the $\mathrm{O}_{2} \mathrm{P}-\mathrm{HR}$ could be used more readily than $\mathrm{RC}$ and $\mathrm{CS}$.
The CCC, also known as the reproducibility index, indicates if the $\mathrm{O}_{2} \mathrm{P}-\mathrm{HR}$ and the CS measurements are precise and accurate at the same time. The closer to 1 the better. The CCC values were moderate, 0.70 for $\mathrm{O}_{2} \mathrm{P}-\mathrm{HR}$ versus $\mathrm{RC}$ and 0.68 for $\mathrm{O}_{2} \mathrm{P}-\mathrm{HR}$ versus $\mathrm{CS}$, which was expected as the technique presented moderate precision. This analysis confirmed the great accuracy $(\mathrm{Cb})$ of the estimates, as the accuracy had to be greater than the coefficient of determination to get a moderate CCC value. In contrast, CCC was greater, 0.90, for CS versus RC.

The mean differences between observed $\left(\mathrm{O}_{2} \mathrm{P}-\mathrm{HR}\right.$ or $\mathrm{CS}$ ) and predicted values (RC or CS) were $2.3 \mathrm{kcal} /$ $\mathrm{BW}^{0.75}$ for $\mathrm{O}_{2} \mathrm{P}-\mathrm{HR}$ versus $\mathrm{RC}, 12.2 \mathrm{kcal} / \mathrm{BW}^{0.75}$ for $\mathrm{CS}$ versus $\mathrm{RC}$, and $20.5 \mathrm{kcal} / \mathrm{BW}^{0.75}$ for $\mathrm{O}_{2} \mathrm{P}-\mathrm{HR}$ versus $\mathrm{CS}$, indicating that $\mathrm{O}_{2} \mathrm{P}-\mathrm{HR}$ measurements were underpredicted relative to $\mathrm{RC}$ and to $\mathrm{CS}$ and $\mathrm{CS}$ was overpredicted relative to RC. However, HP means did not differ among the 3 assessed techniques (Table 1). The mean square error of prediction calculation confirmed that most of the error associated with the $\mathrm{O}_{2} \mathrm{P}-\mathrm{HR}$ method was random error (66.4\% compared with RC and $59.5 \%$ compared with CS; Table 2).

The $\mathrm{O}_{2} \mathrm{P}-\mathrm{HR}$ method generated HP estimates that were comparable to HP estimated using RC and CS across a range of DMI with great accuracy and moderate precision. The CS estimated HP compared with RC with great accuracy and also great precision. The $\mathrm{O}_{2} \mathrm{P}-$ HR method had a greater between-animal coefficient of variation, which has a negative effect on the power of an experiment using the $\mathrm{O}_{2} \mathrm{P}-\mathrm{HR}$ method. However, despite this loss in statistical power, it is an alternative technique for those that do not have respiration chambers or who wish to avoid slaughtering animals and estimating DMI and MEI (needed to estimate HP by using CS), especially under grazing conditions. In general, this method can be useful for the study of energy metabolism in cattle. Further studies should be performed to investigate ways to minimize errors associated with the $\mathrm{O}_{2} \mathrm{P}-\mathrm{HR}$ method to increase the precision and the statistical power of experiments using this technique.

\section{ACKNOWLEDGMENTS}

The results from this study are part of the results of the project "Nutrição de Precisão" of EMBRAPA. The authors gratefully acknowledge the funding support from Conselho Nacional de Desenvolvimento Científico e Tecnológico $(\mathrm{CNPq})$, Coordenação de Aperfeiçoamento de Pessoal de Nível Superior (CAPES), Fundação de Amparo à Pesquisa do estado de Minas Gerais (FAPEMIG), and Empresa Brasileira de Pesquisa Ag- 
ropecuária (EMBRAPA) of Brazil. The author D.B.O. gratefully acknowledges CAPES/EMBRAPA for the doctoral scholarship.

\section{REFERENCES}

Arieli, A., A. Kalouti, Y. Aharoni, and A. Brosh. 2002. Assessment of energy expenditure by daily heart rate measurement-Validation with energy accretion in sheep. Livest. Prod. Sci. 78:99-105. http://dx.doi.org/10.1016/S0301-6226(02)00094-5.

Bibby, J., and H. Toutenburg. 1977. Prediction and Improved Estimation in Linear Models. Wiley, Berlin, Germany.

Brosh, A. 2007. Heart rate measurements as an index of energy expenditure and energy balance in ruminants: A review. J. Anim. Sci. 85:1213-1227. http://dx.doi.org/10.2527/jas.2006-298.

Brosh, A., Y. Aharoni, and Z. Holzer. 2002. Energy expenditure estimation from heart rate: Validation by long-term energy balance measurement in cows. Livest. Prod. Sci. 77:287-299. http://dx.doi. org/10.1016/S0301-6226(02)00033-7.

Brouwer, E. 1965. Report of sub-committee on constants and factors. Pages 441-443 in Energy Metabolism of Farm Animals, Academic Press, London, UK.

Chaokaur, A., T. Nishida, I. Phaowphaisal, and K. Sommart. 2015. Effects of feeding level on methane emissions and energy utilization of Brahman cattle in the tropics. Agric. Ecosyst. Environ. 199:225-230. http://dx.doi.org/10.1016/j.agee.2014.09.014.

Costa e Silva, L. F., S. C. Valadares Filho, T. E. Engle, P. P. Rotta M. I. Marcondes, F. A. S. Silva, E. C. Martins, and A. T. Toku- naga. 2015. Macrominerals and trace element requirements for beef cattle. PLoS ONE 10:e0144464. http://dx.doi.org/10.1371/ journal.pone.0144464.

Liao, J. J. Z. 2003. An improved concordance correlation coefficient. Pharm. Stat. 2:253-261. http://dx.doi.org/10.1002/pst.52.

Lin, L. I.-K. 1989. A concordance correlation coefficient to evaluate reproducibility. Biometrics 45:255-268.

Machado, F. S., T. R. Tomich, A. L. Ferreira, L. F. L. Cavalcanti, M. M. Campos, C. A. V. Paiva, M. N. Ribas, and L. G. R. Pereira. 2016. Technical note: A facility for respiration measurements in cattle. J. Dairy Sci. 99:4899-4906. http://dx.doi.org/10.3168/ jds.2015-10298.

McLean, J. A. 1972. On the calculation of heat production from opencircuit calorimetric measurements. Br. J. Nutr. 27:597-600.

Neter, J., M. H. Kutner, C. J. Nachtsheim, and W. Wasserman. 1996. Applied Linear Statistical Models, 5th ed. McGraw-Hill, Boston, MA.

NRC. 1996. Nutrient Requirements of Beef Cattle. National Academy Press, Washington, DC.

Oss, D. B., M. I. Marcondes, F. S. Machado, L. G. R. Pereira, T. R. Tomich, G. O. Ribeiro Jr., M. L. Chizzotti, A. L. Ferreira, M. M. Campos, R. M. Mauricio, A. V. Chaves, and T. A. McAllister. 2016. An evaluation of the face mask system based on short-term measurements compared with the sulfur hexafluoride $\left(\mathrm{SF}_{6}\right)$ tracer, and respiration chamber techniques for measuring $\mathrm{CH}_{4}$ emissions. Anim. Feed Sci. Technol. 216:49-57. http://dx.doi.org/10.1016/j. anifeedsci.2016.03.008

Tedeschi, L. O. 2006. Assessment of the adequacy of mathematical models. Agric. Syst. 89:225-247. http://dx.doi.org/10.1016/j. agsy.2005.11.004. 